
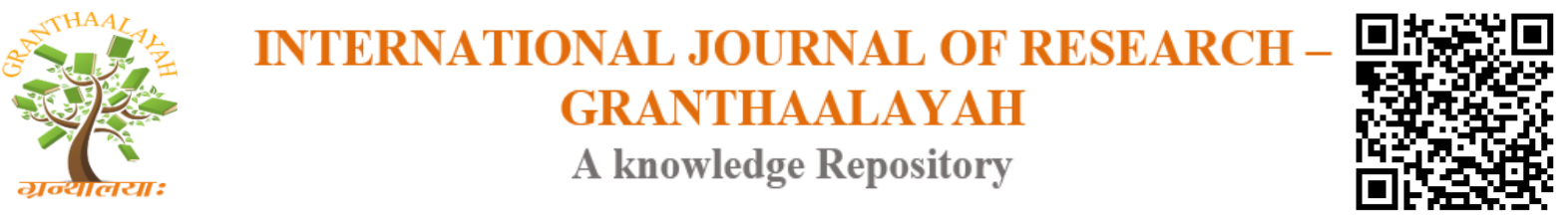

Science

\title{
PSYCHOLOGICAL EXPERIENCE OF CLIENTS DIAGNOSED WITH GLAUCOMA IN TWO SELECTED EYE CLINICS IN ACCRA, GHANA
}

\author{
Bruce, Daniel $^{* 1}$, Eshun, V. Mawuli ${ }^{2}$ \\ ${ }^{* 1,2}$ Methodist University College Ghana, Department of Psychology, P.O. Box DC940, \\ Dansoman, Accra, Ghana
}

\begin{abstract}
The aim of this study was to find out the prevalence of psychosocial problems among persons living with glaucoma and also find out whether socio-demographic characteristics of glaucoma patients significantly affect their levels of psychosocial distress. The cross-sectional survey design was chosen. One hundred (100) patients with glaucoma were selected from two Eye clinics in Accra as the sampled population. One-Way ANOVA, independent t-test and Pearson correlation were used for data analysis. Results from the analysis showed that $99 \%$ of the patients reported mild to extremely severe depression. One percent $(1 \%)$ of the sample reported normal depression levels. It was also observed from the analysis that $75 \%$ of the patients reported mild to extremely severe anxiety levels and, $25 \%$ reported normal anxiety levels. On stress levels, $45 \%$ of glaucoma patients reported mild to severe stress levels whilst $55 \%$ of reported normal stress levels. Further analysis showed that female glaucoma patients reported higher depression, anxiety and stress levels than male glaucoma patients, younger glaucoma patients reported higher depression, anxiety and stress levels than older glaucoma patients. However, no statistically significant differences exist among Glaucoma patients who are employed, unemployed and self-employed in their depression and anxiety levels but differed significantly on their stress levels. No statistically significant differences exist among Glaucoma patients who are single, married, widowed and divorced in their depression and anxiety levels but differed significantly on their stress levels. Additionally, there is a significant positive relationship between patients' social distress and emotional distress (DASS). It is concluded that there is substantial level of psychosocial distress among patients with glaucoma. Patients' age, sex and marital status significantly affecting their psychosocial distress and therefore, psychosocial care should be included in the healthcare of these patients.
\end{abstract}

Keywords: Glaucoma Patients; Emotional Distress; Psychosocial Distress; Psychosocial Problems; Psychosocial Care; and Social Distress.

Cite This Article: Bruce, Daniel, and Eshun, V. Mawuli. (2017). "PSYCHOLOGICAL EXPERIENCE OF CLIENTS DIAGNOSED WITH GLAUCOMA IN TWO SELECTED EYE CLINICS IN ACCRA, GHANA." International Journal of Research - Granthaalayah, 5(9), 52-67. https://doi.org/10.29121/granthaalayah.v5.i9.2017.2198. 


\section{Introduction}

\subsection{Background to the Study}

Transition through life's journey comes with its own psychosocial as well as physical problems. One of the most notable physical challenges in old age is an eye problem commonly referred to as glaucoma. Sandford-Smith (2004) defined Glaucoma as a common disease of the eye which is the second most common cause of world blindness after cataract. Sandford-Smith (2004) explains further that in Glaucoma, the intraocular pressure rises, and the first tissue to be damaged is the optic nerve at the point where it enters the eye. Sandford-Smith (2004) goes on to explain that there are many causes of Glaucoma but the most common one are primary open angle and Angle Closure Glaucoma. Blindness due to this type of Glaucoma is irreversible and as a result, much attention is needed to be giving to the eye.

According to Faal (2012) primary Open-angle glaucoma is sometimes called the "thief of sight". This is because blindness due to Glaucoma is irreversible and there is no pain or discomfort. Vision loss is so gradual that people often do not notice it. It cannot be cured as it is a chronic condition which requires ongoing treatment for the remainder of a patient's life. Although the vision loss caused by Glaucoma is irreversible, medication or surgery can usually control the pressure within the eye and slow or halt the progression of the disease. Thus, if the disease is diagnosed in its early stages, it can be treated effectively, and vision can usually be preserved (Friedlaender, 2009). However, most people have fears and misconceptions about losing their sight and as a result clients with glaucoma need trust and encouragement by their relatives to seek attention. Furthermore, several risk factors have been noted to predispose individuals to developing glaucoma (Dawoda, Otakpor \& Ukponmwam, 2004). One of the most commonly cited risk factors for developing glaucoma is age of the individual. It is observed that glaucoma affects about 2 percent of people over age 40, and about 8 percent of people over age 70 . Similarly, family history of glaucoma and race of individuals have been implicated in development of glaucoma. For instance, it is reported that although the pattern of inheritance is not regular and predictable, the disease runs in families. Some medical conditions such as diabetes, nearsightedness, high blood pressure, and long-term use of cortisone or other steroid medications have been implicated in developing glaucoma. Additionally, it is important to note that glaucoma does not manifest in the same way but occurs in two main forms; namely, Chronic simple and Acute Glaucoma. In chronic simple Glaucoma, pressure within the eye rises gradually, and vision loss progresses over a period of years. Chronic Simple Glaucoma is also known as Open-Angle Glaucoma because the angle between the cornea and iris remains normal. This study focuses on chronic simple Glaucoma, which accounts for 95 percent of all cases of Glaucoma (Wu, Guo, Xia, Lu \& Xi, 2011).

However, in acute Glaucoma the pressure inside the eye rises suddenly and immediate medical treatment is necessary to preserve vision. Acute Glaucoma is also known as Narrow-Angle or Angle-Closure Glaucoma, because the angle between the cornea (the transparent layer of tissue at the front of the eye) and the iris (the colored part of the eye) becomes smaller than normal (Wu, Guo, Xia, Lu \& Xi, 2011). 
Glaucoma is the world's leading cause of irreversible blindness; approximately 4.5 million people worldwide are blind due to Glaucoma (Johnson et al. 2011). The World Health Organization(WHO) estimated that about 4.4 million blind people were as a result of Glaucoma which represents $12.3 \%$ of the blind globally (Krishnadas\&Puthuran, 2009).Worldwide, approximately 6.7 million people have significant vision loss in both eyes due to Glaucoma, making this condition the second leading cause of blindness. About 120,000 people in the United States alone have significant bilateral vision loss due to glaucoma, and the condition is the leading cause of preventable blindness in the nation. More than 2 million people are currently being treated for Glaucoma, and an estimated 1 million additional cases of the disease are undiagnosed (Friedlaender, 2009).

According to Glaucoma Today Online, 2014, glaucoma is the second leading cause of blindness in Africa after cataract; Glaucoma is responsible for approximately $15 \%$ of blindness on the continent. Despite having the highest incidence and prevalence of Glaucoma in the world, the African region has only recently recognized glaucoma as a priority eye disease, according to Vision 2020 initiatives. Glaucoma in Sub Saharan Africa is a devastating and often neglected disease which most communities stigmatized it with superstitious beliefs. One of the factors that may cause the delay of patients reporting could be attributed to the fact that about $80 \%$ or more of the population live in rural areas, while the majority of ophthalmologists reside in urban centres. In many regions of Sub Saharan Africa, the ophthalmologist-patient ratio is 1: 1 million people. The shortage of trained eye care professionals is linked to limited number of eye hospitals, the majority of which are located in urban centres. Public health initiatives targeting Glaucoma in Sub Saharan Africa must address factors underlying a lack of public awareness of Glaucoma.

Although some individuals tend to adjust quite well with some form of illnesses, a diagnosis of a serious eye disease such as glaucoma which can lead to blindness has significant emotional impact on the patient and their relatives as the diagnosis requires changing roles in the family and society (Dawoda, Otakpor \& Ukponmwan, 2004; Wu, Guo, Xia, Lu \& Xi, 2011). Research evidence has suggested that psychiatric comorbidity in glaucoma patients could negatively impact their compliance behaviour. For instance, Pappa et al (2006) found from their study that the presence of depression among persons living with glaucoma complied poorly with their treatment regimen compared to their counterparts with no comorbid depression. This noncompliant behaviour among the patients could affect the long term prognosis and course of the illness.

It has been reported that persons living with Glaucoma which is a progressive disease are likely to experience emotional stress due to nature of their therapies which are usually aggressive over frequent clinical visits and subjective awareness of a decline in visual function (DiMatteo, Lepper \& Croghan, 2000; Lundmark, Trope, Shapiro \& Flanagan, 2009). That is, since the patients are aware that their condition gets worse with passage of time and they are likely to lose their sight, feelings of sadness, apprehension, helplessness and hopelessness become common feelings. The prevalence of psychological distress, non-compliance issues, depression and anxiety among persons living with glaucoma have been associated some patients' demographic characteristics such as sex, age, income, education and duration of illness. For instance, Dawoda, Otakporand Ukponmwan (2004) found from their study in Nigeria that lack of formal education 
significantly predicted psychiatric morbidity among persons living with glaucoma. It was also noted that depression was higher among patients aged 50 years and above than those aged less than 50 years whiles patients less than 50years reported higher anxiety level than patients above 50 years. These differences in reported psychological distress due to patients' demographic characteristics have been reported by other researchers (Dunlop, Lyons, Manheim, Song \& Chang, 2004).

The challenge to the patients living with glaucoma is twofold as the patients have to deal with issues affecting their sight as well as the psychosocial impacts. For instance, the glaucoma may result in loss of employment as sight problems might hinder the individual's performance at the workplace. The financial burden of long term treatment for the glaucoma also may affect the family dynamics as resources will be diverted to treatment of the illness which hitherto would have been used for other businesses. These challenges coupled with the physical threats posed by the disease tend to result in severe emotional distress which needs to be addressed holistically in the provision of healthcare.

\section{Statement of the Problem}

Various studies in different countries in Sub Saharan Africa have established a significantly higher prevalence of Glaucoma. The recent Tema Eye Survey in Ghana found an overall prevalence of primary open-angle Glaucoma in people over age 40 of $6.8 \%$ that increased to $14.6 \%$ among those 80 years and older (Debrah, 2014). Debrah (2014) also asserted that Ghana is a leading country with the highest Glaucoma cases of 700,000 with 35, 000 patients going blind. He further stated 24,000 Ghanaians are blind with half of the figure being victims of cataract, a clouding of the lens of the eye that impairs vision.

Abutiate (2014) indicates that Glaucoma continues to be a major public health menace and it remains the cause of irreversible blindness in the world. He pointed out that as over 6 to 8 million people who are living with Glaucoma and about half of those figures do not know they have the condition, while over one million people have become blind as a result of Glaucoma. It is estimated that about 60,000 Ghanaians are affected by the eye disease and out of them 25, 000 are said to be aware of their medical condition. The eye is a small but delicate organ which serves as a "window" to the body, (Sandford-Smith, 2004). It will therefore, be appropriate to protect it. The eye controls most of the organs so any damage to it is a serious issue.

It is interesting to note that although several research findings have pointed out the burden of glaucoma, little attention is paid to the psychosocial experiences of these patients and how they deal with them. The question that remains unanswered is whether their psychosocial experiences of glaucoma patients are taken into consideration in providing healthcare to the patients? Are the glaucoma patients receiving holistic care which includes counselling concerning their illness? These and many other concerns formed the basis for this research to address the issues relating to the psychological functioning of glaucoma patient

\section{Statement of Hypothesis}

The following hypotheses were formulated. 
1. Female glaucoma patients are more likely to report higher depression, anxiety and stress levels than male glaucoma patients.

2. Younger glaucoma patients are more likely to report higher depression, anxiety and stress levels than older glaucoma patients.

3. Unemployed glaucoma patients are more likely to report higher depression, anxiety and stress levels than self-employed and employed glaucoma patients.

4. Single glaucoma patients are more likely to report higher depression, anxiety and stress levels than married glaucoma patients.

5. There will be a significant positive relationship between social distress depression, anxiety and stress scores (DASS score).

\section{Methodology}

\section{Research Design}

The cross-sectional survey design was chosen for the study because it allows for collection of data from a relatively large sample within the shortest possible time of this study

\section{Population}

The population for this study was Glaucoma patients who reported at the selected Eye Clinics for medical attention. This population was chosen because the Eye Clinics attend to people from different ethnic and socio-cultural backgrounds. Thus, the population will not be biased towards any particular ethnic group in the study.

\section{Sample and Sampling technique}

The non-probability sampling of purposive type was adopted to select Glaucoma patients from the Emmanuel Eye Clinic and Cocoa Clinic's Eye Clinic because these two eye clinics are well known for the treatment of eye conditions and record high daily attendance. The convenient sampling technique was used to select one hundred respondents from the Glaucoma patients. This technique was the most appropriate in the face of the resource and time constrains and the willingness of the available patients to take part in the study.

\section{Research Instruments/Tools}

\section{Anxiety and Stress Scale}

Items fall into three scales: Depression (D), Anxiety (A) and Stress (S) with 7 items per scale. Each item is scored from 0 ("did not apply to me at all") to 3 ("applied to me very much, or most of the time") in terms of how much the item applied to the individual within the past week. The total scores were multiplied by 2 to obtain the scores to reflect the original 42 item scale.

\section{Depression, Anxiety Stress Scale (DASS-21)}

On the DASS, a depression score of 0-9 is classified as Normal depression, a score of 10-13 is classified as Mild depression, a score of 14-20 is classified as Moderate depression, a score of 21-27 is classified as Severe depression and a score 28 and above is classified as Extremely severe depression. For anxiety levels, a score of 0-7 is classified as Normal anxiety, a score of 89 is classified as Mild anxiety, a score of 10-14 is classified as Moderate anxiety, a score of 1519 is classified as severe anxiety and a score of 20 and above is classified as extremely severe 
anxiety. For stress levels, a score of 0-14 is classified as Normal stress, a score of 15-18 is classified as Mild stress, a score of 19-25 is classified as Moderate stress, a score of 26-33 is classified as severe stress and a score of 38 and above is classified as extremely severe stress. The internal consistencies of the three subscales were 0.71 for depression, 0.79 for anxiety and 0.81 for stress (Lovibond \& Lovibond, 1995).

\section{Social Distress Questionnaire}

This is a 10 item self-developed scale to assess the specific distress associated with living with Glaucoma in terms of financial cost, emotional burden and health implications. Each item is scored from 0 ("did not apply to me at all") to 3 ("applied to me very much, or most of the time"). The total score of the scale could range between 0 and 30 with higher scores reflecting more Glaucoma-related distress and lower score indicate lower Glaucoma-related distress respectively. The scale has an internal consistency of $\alpha=.83$ which indicates high reliability. There was a portion on the scale for demographic data on the sampled population.

\section{Data Collection Procedure}

Letters of introduction were sent to the managements of the two health facilities with eye care services. The aims/objectives of the study were explained and after managements of the two health facilities granted permission for the data collection, dates were fixed for the data collection. The participants were informed that participation in the study was voluntary and their refusal to participate would not in anyway, affect the healthcare they receive. Those who consented to be part of the study were given the questionnaires to complete. The completion of the questionnaires lasted between 30minutes to 1 hour depending on the reading speed of the individual patients. The completed questionnaires were retrieved for coding and analysis.

\section{Data Analysis}

For the data analysis, hypothesis one was analyzed with independent t-tests as two groups of patients were compared. Hypotheses 2, 3 and 4 were analyzed with the One-Way analysis of variance as more than two groups were compared on their levels of depression, anxiety and stress. The 5 hypothesis was analyzed using the Pearson correlation as the variables were assumed to be linearly related and measured on interval scales.

\section{Results}

\subsection{Descriptive Statistics}

The Table 1 below presents the descriptive statistics of the key variables in the study by presenting the means, standard deviations and the Cronbach alpha of the scales.

Table 1: Summary of Descriptive Statistics of the Variables in the Study

\begin{tabular}{llll}
\hline VARIABLES & MEAN & STD DEV. & RELIABILITY ( $\boldsymbol{\alpha})$ \\
\hline Depression & 9.59 & 2.31 & .61 \\
Anxiety & 8.97 & 2.88 & .72 \\
Stress & 7.21 & 3.13 & .68 \\
Social Distress & 11.59 & 4.77 & .83 \\
\hline
\end{tabular}




\subsection{Testing of Hypotheses}

The results of the stated hypotheses are discussed below,

Table 2: Prevalence of Depression, Anxiety and Stress among Glaucoma Patientsin the study

\begin{tabular}{llll}
\hline SEVERITY & Depression (\%) & Anxiety (\%) & Stress (\%) \\
\hline Normal & 1 & 25 & 55 \\
Mild & 6 & 20 & 20 \\
Moderate & 55 & 31 & 16 \\
Severe & 34 & 19 & 9 \\
Extremely Severe & 4 & 5 & -
\end{tabular}

Table 2: shows that $99 \%$ of the patients reported mild to extremely severe depression with the most reported case being moderate depression (55\%) followed by severe depression (34\%). Only $1 \%$ of the sample reported normal depression levels. It was also observed from the analysis that $75 \%$ of the patients reported mild to extremely severe anxiety levels. The most reported case is the moderate anxiety (31\%) followed by mild anxiety (20\%). However, $25 \%$ of the glaucoma patients reported normal anxiety levels. On stress levels, $45 \%$ of glaucoma patients sampled for the study reported mild to severe stress levels with the most reported case is mild stress (20\%) followed by moderate stress levels (16\%). However, 55\% of glaucoma patients reported normal stress levels.

Hypothesis One: Female glaucoma patients are more likely to report higher depression, anxiety and stress levels than male glaucoma patients. This hypothesis compares two groups of male and female patients on their levels of depression, anxiety and stress as shown in the Table 3.

Table 3: Summary of Independent t-Test of Gender Differences in the Levels of Depression, Anxiety and Stress

\begin{tabular}{|c|c|c|c|c|}
\hline Variables & Male $(n=62)$ & Female $(n=38)$ & $t(d f=98)$ & $\rho$ \\
\hline Depression & $\begin{array}{l}19.35 \\
(\mathrm{SD}=4.87)\end{array}$ & $\begin{array}{l}22.00 \\
(\mathrm{SD}=4.70)\end{array}$ & 2.67 & .009 \\
\hline Anxiety & $\begin{array}{l}17.18 \\
(\mathrm{SD}=5.55)\end{array}$ & $\begin{array}{l}20.50 \\
(\mathrm{SD}=5.60)\end{array}$ & 2.90 & .005 \\
\hline Stress & $\begin{array}{l}14.13 \\
(\mathrm{SD}=6.29)\end{array}$ & $\begin{array}{l}16.89 \\
(\mathrm{SD}=6.20)\end{array}$ & 2.15 & .034 \\
\hline
\end{tabular}

Table 3above shows that gender of patients has statistically significant effect on their depression levels, $\mathrm{t}(98)=2.67, \rho<.05$. It was also observed that patients' gender has significant effect on their anxiety levels at the .05 alpha level, $\mathrm{t}(98)=2.90, \rho<.05$. It was also observed from the table above that significant gender difference exists between male and female patients in their stress levels, $t(98)=2.15, \rho<.05$. The results showed that female glaucoma patients reported higher depression, anxiety and stress levels, thus, the first hypothesis that female glaucoma patients are more likely to report higher depression, anxiety and stress levels than male glaucoma patients is supported. 
Hypothesis Two: Younger glaucoma patients are more likely to report higher depression, anxiety and stress levels than older glaucoma patients. This hypothesis compares three age groups of participants on their depression, anxiety and stress levels. The ANOVA results are summarized in the Table 5;

Table 4: One-Way ANOVA of Age Differences in Depression, Anxiety and Stress among Glaucoma Patients

\begin{tabular}{|c|c|c|c|c|c|}
\hline Variables & $\begin{array}{l}\text { Less than } 45 y r s \\
(n=26)\end{array}$ & $\begin{array}{l}\text { 46-60yrs } \\
(n=44)\end{array}$ & $\begin{array}{l}\text { 60yrs \& above } \\
(n=30)\end{array}$ & $\mathbf{F}(2,97)$ & $\boldsymbol{\rho}$ \\
\hline Depression & $\begin{array}{l}23.50 \\
(\mathrm{SD}=3.98)\end{array}$ & $\begin{array}{l}19.05 \\
(\mathrm{SD}=4.89)\end{array}$ & $19.57(\mathrm{SD}=4.74)$ & 8.21 & .001 \\
\hline Anxiety & $\begin{array}{l}21.85 \\
(\mathrm{SD}=3.56)\end{array}$ & $\begin{array}{l}17.50 \\
(\mathrm{SD}=5.12)\end{array}$ & $16.87(\mathrm{SD}=7.04)$ & 6.98 & .001 \\
\hline Stress & $\begin{array}{l}17.69 \\
(\mathrm{SD}=5.53)\end{array}$ & $\begin{array}{l}12.73 \\
(\mathrm{SD}=5.51)\end{array}$ & $16.00(\mathrm{SD}=7.09)$ & 6.73 & .002 \\
\hline
\end{tabular}

An examination of the ANOVA Table 4 indicates that significant age differences exist between at least two of the age groups in their levels of depression at the .05 alpha level, $F(2,97)=8.21, \rho$ $<.05$. Significant age differences exist between at least two of the age groups in their levels of anxiety at the .05 alpha level, $F(2,97)=6.98, \rho<.05$. It was further observed that significant age differences exist between at least two of the age groups in their patients' stress levels, $\mathrm{F}(2,97)=6.73, \rho<.05$. Since there are more than two groups and the three F-ratios are significant; multiple comparisons were computed for levels of depression, anxiety and stress. The summary of the multiple comparisons of the age groups are presented in the Tables 5 to 7;

Table 5: Multiple comparisons of Age Differences in Patients' Depression using Bonferroni Test

\begin{tabular}{llll}
\hline Groups & Less than 45years & 46-60years & 60years \& above \\
\hline Less than 45years & - & $4.45^{*}$ & $3.93^{*}$ \\
46-60years & & - & .52 \\
60years \&above & & & - \\
\hline
\end{tabular}

*= significant at the .05 alpha level

Results from Table 5 shows that glaucoma patients less than 45years of age reported higher depression levels than patients between 46 and 60 years $(t=4.45, \rho<.05)$ and patients who are 60 years and above $(\mathrm{t}=3.93, \rho<.05)$. However, no significant mean difference was observed between patients who are aged 46-60years and patients of age 60years and above $(\mathrm{t}=.52, \rho>$ $.05)$ in their depression levels.

Table 6: Multiple comparisons of Age Differences in Patients' Anxiety using Bonferroni Test

\begin{tabular}{llll}
\hline Groups & Less than 45years & 46-60years & 60years \& above \\
\hline Less than 45years & - & $4.35^{*}$ & $4.98^{*}$ \\
46-60years & - & .63 \\
60years \&above & & - \\
\hline * significant at the .05 alpha level
\end{tabular}


Results from Table 6 shows that glaucoma patients less than 45years of age reported higher anxiety levels than patients between 46 and 60 years $(\mathrm{t}=4.35, \rho<.05)$ and patients who are 60 years and above $(\mathrm{t}=4.98, \rho<.05)$. However, no significant mean difference was observed between patients who are aged 46-60years and patients of age 60years and above $(\mathrm{t}=.63, \rho>$ $.05)$ in their anxiety levels.

Table 7: Multiple comparisons of Age Differences in Patients' Stress using Bonferroni Test

\begin{tabular}{llll}
\hline Groups & Less than 45years & 46-60years & 60years \& above \\
\hline Less than 45 years & - & $4.97^{*}$ & 1.09 \\
46-60 years & - & $3.87^{*}$ \\
60 years \&above & & & - \\
\hline
\end{tabular}

*= significant at the .05 alpha level

Results from table 7 shows that glaucoma patients less than 45years of age reported higher stress levels than patients between 46 and 60 years $(t=4.97, \rho<.05)$. No significant mean difference was observed in stress levels between patients who are less than 45years and patients who are 60 years and above $(t=1.09, \rho>.05)$. However, a significant mean difference was observed between patients who are aged 46-60years and patients of age 60years and above $(\mathrm{t}=3.87, \rho<.05)$ in their stress levels. Hypothesis two that states younger glaucoma patients are more likely to report higher depression, anxiety and stress levels than older glaucoma patients is supported.

Hypothesis Three: Unemployed glaucoma patients are more likely to report higher depression, anxiety and stress levels than self-employed and employed glaucoma patients.

The One-Way ANOVA was used to compare the three groups on their depression, anxiety and stress levels. The results are summarized in the Table 8;

Table 8: Differences in Depression, Anxiety and Stress due to Employment Status of Patients

\begin{tabular}{|c|c|c|c|c|c|}
\hline $\begin{array}{l}\text { Dependent } \\
\text { Variables }\end{array}$ & $\begin{array}{l}\text { Employed } \\
(n=46)\end{array}$ & $\begin{array}{l}\text { Unemployed } \\
(n=42)\end{array}$ & $\begin{array}{l}\text { Self-employed } \\
(n=12)\end{array}$ & $\mathbf{F}(2,97)$ & $\boldsymbol{\rho}$ \\
\hline$\overline{\text { Depression }}$ & $\begin{array}{l}20.91 \\
(\mathrm{SD}=5.21)\end{array}$ & $\begin{array}{l}19.45 \\
(\mathrm{SD}=4.44)\end{array}$ & $\begin{array}{l}21.42 \\
(\mathrm{SD}=5.53)\end{array}$ & 1.27 & .29 \\
\hline Anxiety & $\begin{array}{l}18.93 \\
(\mathrm{SD}=5.56)\end{array}$ & $\begin{array}{l}18.33 \\
(\mathrm{SD}=6.14)\end{array}$ & $\begin{array}{l}16.92 \\
(\mathrm{SD}=5.45)\end{array}$ & .58 & .56 \\
\hline Stress & $\begin{array}{l}13.48 \\
(\mathrm{SD}=5.75)\end{array}$ & $\begin{array}{l}16.71 \\
(\mathrm{SD}=7.04)\end{array}$ & $\begin{array}{l}16.33 \\
(\mathrm{SD}=4.74)\end{array}$ & 3.19 & .04 \\
\hline
\end{tabular}

An examination of Table 8, the results showed that no statistically significant difference exists in the depression levels among patients who are employed, unemployed and self-employed at the .05 alpha level, $\mathrm{F}(2,97)=1.27, \rho>05$. Employment status of glaucoma patients did not have any statistically significant effect on their anxiety levels, $F(2.97)=.58, \rho>.04$. F (2.97) $=3.19, \rho$ $<.05$. Since there are three employment statuses, the multiple comparisons were performed and the results are summarized in the Table 9; 
Table 9: Multiple Comparisons of Differences in Stress due to Employment Status of Patients using Bonferroni

\begin{tabular}{llll}
\hline Groups & Employed & Unemployed & Self-employed \\
\hline Employed & - & $3.24^{*}$ & 2.86 \\
Unemployed & & - & .38 \\
Self-employed & & & - \\
\hline
\end{tabular}

*= significant at the .05 alpha level

Analysis of the multiple comparison Table 9 indicates that significant difference exists between only glaucoma patients who are employed and those who are unemployed $(t=3.24, \rho<.05)$. However, no significant mean differences exist between patients who are employed and selfemployed $(\mathrm{t}=2.86, \rho>.05)$, patients who are unemployed and patients who are self-employment $(\mathrm{t}=.38, \rho>.05)$. Therefore, the third hypothesis that unemployed glaucoma patients are more likely to report higher depression, anxiety and stress levels than self-employed and employed glaucoma patients is not supported.

Hypothesis Four: Single glaucoma patients are more likely to report depression, anxiety and stress levels than married glaucoma patients.

One-Way ANOVA was used to compare the three groups on their depression, anxiety and stress levels. The results are summarized in the Table 10;

Table 10: Summary of Differences in Depression, Anxiety and Stress due to Patients' Marital Status

\begin{tabular}{|c|c|c|c|c|c|c|}
\hline Variables & $\begin{array}{l}\text { Single } \\
(n=8)\end{array}$ & $\begin{array}{l}\text { Married } \\
(n=86)\end{array}$ & $\begin{array}{l}\text { Divorced } \\
(n=3)\end{array}$ & $\begin{array}{l}\text { Widowed } \\
(\mathrm{n}=3)\end{array}$ & $F(3,96)$ & $\rho$ \\
\hline Depression & $\begin{array}{l}17.75 \\
(\mathrm{SD}=4.06)\end{array}$ & $\begin{array}{l}20.56 \\
(\mathrm{SD}=5.07)\end{array}$ & $\begin{array}{l}22.67 \\
(\mathrm{SD}=4.62)\end{array}$ & $\begin{array}{l}19.33 \\
(\mathrm{SD}=2.31)\end{array}$ & 1.05 & .38 \\
\hline Anxiety & $\begin{array}{l}20.50 \\
(\mathrm{SD}=4.11)\end{array}$ & $\begin{array}{l}18.07 \\
(\mathrm{SD}=6.01)\end{array}$ & $\begin{array}{l}22.67 \\
(\mathrm{SD}=1.15)\end{array}$ & $\begin{array}{l}19.33 \\
(\mathrm{SD}=2.30)\end{array}$ & 1.02 & .39 \\
\hline Stress & $\begin{array}{l}18.00 \\
(\mathrm{SD}=6.68)\end{array}$ & $\begin{array}{l}14.51 \\
(\mathrm{SD}=6.18)\end{array}$ & $\begin{array}{l}26.00 \\
(\mathrm{SD}=.00)\end{array}$ & $\begin{array}{l}16.00 \\
(\mathrm{SD}=.00)\end{array}$ & 4.09 & .01 \\
\hline
\end{tabular}

The Table 10 shows that patients' marital status did not have any significant effect on their depression levels at the .05 alpha level, $F(3,96)=1.05, \rho>.05$. Similarly, patients' marital status did not have any significant effect on their anxiety levels at the .05 alpha level, $\mathrm{F}(3,96)=$ $1.02, \rho>.05$. However, patients' marital status had a significant effect on their stress levels at the .05 alpha level, $\mathrm{F}(3,96)=4.09, \rho<.05$. Since the marital status groups were more than two the post-hoc analysis was performed and the results are summarized in the Table 12; 
Table 11: Multiple comparisons of differences in Stress levels of Patients due to their Marital

\begin{tabular}{lllll}
\multicolumn{5}{c}{ Status } \\
\hline Groups & Single & Married & Divorced & Widowed \\
\hline Single & - & 3.49 & 8.00 & 2.00 \\
Married & - & $11.49^{*}$ & 1.49 \\
Divorced & & & - & 4.97 \\
Widowed & & & & - \\
\hline
\end{tabular}

*= significant at the .05 alpha level

A critical analysis of the multiple comparisons Table 11 shows that a significant mean difference exists between married and divorced patients with divorced patients reporting more stress at the .05 alpha level $(t=11.49, \rho<.05)$. No significant mean differences were observed in the other groups in their stress levels at the .05 alpha level. Therefore, the fourth hypothesis that single glaucoma patients are more likely to report depression, anxiety and stress levels than married glaucoma patients is supported.

Hypothesis Five: There will be a significant positive relationship between Social Distress and DASS score (Depression, Anxiety and Stress)

To test which hypothesis gives the Pearson correlation was used and the results are summarized

Table 12: Summary of Pearson Correlation of the relationship between Patients' Emotional Distress and Social Distress

\begin{tabular}{llllll}
\hline VARIABLES & Mean & SD & df & r & p \\
\hline Emotional Distress (DASS) & 53.90 & 12.34 & 98 & .40 & .001 \\
Social Distress & 11.59 & 4.77 & & & \\
\hline
\end{tabular}

From Table 12, it was observed that a significant positive relationship exists between the levels of emotional distress and social distress among the patients at the .05 level of significance, $r(98)$ $=.40, \rho=.001$. Therefore, the fifth hypothesis that there will be a significant positive relationship between Social Distress and DASS score (Depression, Anxiety and Stress

\section{Discussion of Findings}

\section{Prevalence of Depression, Anxiety and Stress among Glaucoma patients}

The present study hypothesized that Glaucoma patients are likely to report higher depression, anxiety and stress levels. Findings from the study showed that Glaucoma patients reported significantly higher depression, anxiety and stress levels with the major psychological problem being depression as majority of patients suffered from mild to extremely severe levels of depression. This means that most individuals living with glaucoma also have co-morbid psychological problems.

This is because glaucoma is a serious condition which can cause blindness and so poses a lot of stress to the individual diagnosed with this condition. The person would have to find ways of coping with the situation which sometimes results in psychological burdens. As posited by Beck 
(1996), individuals faced by stressful life situations are likely to engage in maladaptive thinking processes in making meaning to the situation which may result in depression or anxiety. For instance a person diagnosed with glaucoma may be battling with the thoughts of whether he or she could be treated effectively or whether he or she will become blind. This is likely to lead to ruining thoughts about impending blindness which explains why anxiety level is high among these patients. In addition, patients who have started losing their sight are likely to be depressed about their inability to do certain things they could hitherto do.

Moreover, from the General Adaptation Syndrome (GAS) point of view which was developed by Selye (1976) every stressful event leaves an effect on the individual. Diagnosis of a serious condition such as glaucoma is no small stress. This is likely to place a lot of demands on both the biological and psychological coping systems of the individual. This explains why level of stress was high among the sample used in this study.

However the level of stress depends on the availability of effective coping resources, which implies that the coping resources determine the level of stress the individual experiences. Secondly, the severity of the stressful event may also play a part on the level of stress. This explains why in this study, though all the participants had glaucoma, $45 \%$ had normal stress level while $55 \%$ had mild to extremely severe levels of stress and the predominant level of stress experienced by these patients was mild.Findings from the present study are consistent with previous studies which reported that glaucoma has a negative impact on the emotional/psychological health and quality of life of patients (Fasih et al., 2010; Kong et al., 2013; Pappa et al., 2006; Tastan et al., 2010; Wu et al., 2010; Yan et al., 2013; Zhou et al., 2013). The findings are however inconsistent with findings from Wilson et al.'s (2002) study which found no significant difference in psychological distress between glaucoma patients and healthy controls.

\section{Demographic Determinants of Depression, Anxiety and Stress among Glaucoma Patients}

\section{The Role of Gender}

It was hypothesized that Female glaucoma patients are more likely to report higher depression, anxiety and stress levels than male glaucoma patients. The results showed that female glaucoma patients reported higher depression, anxiety and stress levels than their male counterparts. Generally, females are reported to experience higher levels of psychological distress compared to their male counterparts (Kessler, McGonagle, Swartz, Blazer, \& Nelson, 1993). This may be due to fact that women have less power in society than men especially in patriarchal societies such as Ghana, which make them more likely to experience certain stressful life events and traumas such as extreme poverty, sexual abuse, harassment and discrimination at the workplace among others. These circumstances pose additional stress and puts strain on the psychological health of women. Therefore, being diagnosed with glaucoma may have a cataclysmic effect on women; making them experience higher psychological impact of the condition than men as stressful experiences are found to have reciprocal effects on each other (Nolen-Hoeksema, 2001). According to Breslau, Davis, Andreski, Peterson, and Schultz, (1997), even when men and women experience same stressors, women are more likely than men to experience greater emotional distress because of gender differences in biological responses to stressors, self-concepts and coping styles (NolenHoeksema, 2001). 
The finding in this study is consistent with Zhou et al.'s (2013) study which found the female gender as one of the risk factors associated with high prevalence of anxiety among glaucoma patients. Tastan et al., (2010) also found similar gender differences such that the anxiety risk in women with glaucoma was found to be 7.5 times higher than in men.

\section{Age Differences}

One of the hypotheses of this study was that younger glaucoma patients are more likely to report higher depression, anxiety and stress levels than older glaucoma patients. Results revealed that, younger glaucoma patients reported higher depression, anxiety and stress levels than older glaucoma patients. It is reported that many older glaucoma patients experienced prolonged sense of hopelessness as many may have suffered treatment failures in the past (Dawoda, et al., 2004), this is likely to result in greater experience of emotional distress than younger patients.

Having a disability or a chronic illness in old age can be very devastating as the elderly already have certain stresses associated with coping with the general decline in physical, psychological and cognitive functioning (Oles \& Oles, 2014). Dealing with glaucoma therefore puts additional strain on their already diminished coping resources which is likely to make them susceptible to psychological problems such as depression, anxiety as well as elevated levels of stress.

In addition, older adults are likely to have other disabilities and physical illnesses aside the eye condition than younger adults which may have a culminating effect on their psychological health. This supports findings from previous studies which found age-related differences in the experience of depression, anxiety and stress among glaucoma patients (Dawoda et al., 2004; Skalicky \& Goldberg, 2008; Zhou et al., 2013).

There is however a suggestion that, age-related differences observed among glaucoma patients may not necessarily be linked with their condition but rather other biological factors (Eramudugolla et al., 2013). Some studies also found younger age rather being a risk factor for anxiety (Mabuchi et al., 2012; Zhou et al., 2013) which is contrary to the present finding.

\section{The Role of Employment Status}

It was also hypothesized that unemployed glaucoma patients are more likely to report higher depression, anxiety and stress levels than self-employed and employedglaucoma patients. Findings revealed that no statistically significant differences exist among Glaucoma patients who are employed, unemployed and self-employed in their depression and anxiety levels but differed significantly on their stress levels.

Economic burden has been found to be one of the risk factors for depression and anxiety among glaucoma patients (Zhou, 2014), which may suggest that people who are employed thus those who have a stable source of income would be less vulnerable to depression and anxiety compared to their unemployed counterparts. However the results of this study disconfirm this assertion as no significant difference was found between employed and unemployed individuals. This could be as a result of the fact that glaucoma treatment is very expensive and even those who are employed still experience high economic burden associated with the condition. Hence an individual's employment status may not be strong enough to cushion him/her from the impact economic burden puts on their psychological health. Dawoda et al., 2004 also did not find employment status to be significantly associated with psychological distress; only education had 
a significant correlation with depression and anxiety. On the other hand, employed individuals experienced less stress compared to unemployed individuals. This may be because employed patients may have a bigger social network from other employees, which could be an effective coping resource to help them deal with their stressors.

\section{Does Marital Status Matter?}

Another hypothesis was that single glaucoma patients are more likely to reporthigherdepression, anxiety and stress levels than married glaucoma patients. It was found out that no statistically significant differences exist among glaucoma patients who are single, married, widowed and divorced in their depression and anxiety levels but differed significantly on their stress levels.

Researchers have reported higher depression and anxiety levels among unmarried glaucoma patients than married ones (Tastan et al., 2010). This was however not the case in the current sample. This is probably because majority of the participants were married and very few were single and divorced, so the effect of marital status on depression and anxiety could not be detected.

Moreover, the ability for marital status to protect individuals from depression and anxiety is dependent on the quality of the marital relationship. It is possible the condition of married glaucoma patients maybe putting a burden on their relationship and hence their marriage may not provide the protective shield from emotional distress.

Nonetheless married patients experienced less stress than divorced patients. This is consistent with Tastan et al.'s (2010) finding. Most divorced individuals end up as single parents which pose a lot of stress. Being divorced is also a stressful life event which causes additional stress for the divorced individual apart from having to deal with the diagnosis of glaucoma.

\section{The relationship between Patients Emotional Distress and Social Distress}

The results showed that the final hypothesis which stated that there will be a significant positive relationship between Social Distress and DASS score (Depression, Anxiety and Stress) is supported. This means that as patients with Glaucoma experiences higher social distress associated with their condition in the form of stigmatization, loss of job, and difficulty in meeting the needs of the family among others, their level of emotional distress in the form of depression, anxiety and stress also increases. This significant relationship between Glaucoma patients' social distress and emotional distress could be due to the fact that the illness places a lot of limitations of the individual which he/she must deal with.

However, when the individual appraises the situation and realizes that there are limited resources available to him or her to deal with the condition, he/she may experience heightened emotional distress in the form of depression, anxiety and stress. This finding is consistent with previous research among persons with an eye problem who reported significant decrease in their quality of life and elevated levels of depression, anxiety and stress. For instance, Wu, et al. (2010) observed that Glaucoma patients' main concern was 'learning to living with it' and have identified coping with daily tasks, living with future uncertainty, and adapting to a decline in life quality as some of the major themes in their study. The uncertainties associated with living with glaucoma and 
decline in quality of life have been significant influence on the level the emotional wellbeing of patients.

\section{Limitations}

The study limited the sample of the study to two eye clinics. This means that the findings cannot be generalized to patients attending other health facilities. These notwithstanding, the reliability and relevance of the findings of the study cannot be disputed. The study makes very relevant contribution to what is known about glaucoma patients in Ghana and sets the pace for more research in that area.

\section{Conclusion}

From the findings, is concluded that, there is a high level of psychosocial distress; depression, anxiety and stress among patients with glaucoma. Female patients' psychological health is affected more by their condition than their male counterparts. Employment status does not significantly shield glaucoma patients from depression and anxiety but influences their stress levels. Similarly patients' age, sex and marital status significantly influence the level of depression and anxiety experienced by glaucoma patients.

\section{Recommendation}

Based on the findings of this study that glaucoma patients experience co-morbid psychological distress, it is recommended that an integrative approach is used in the treatment of glaucoma patients. This integrative approach should include psychiatric/psychological evaluation and treatment rather than just focusing on medical treatment of the condition. In addition, as glaucoma poses additional stress to the individual which results in high levels of stress among patients, patients need to be taught effective coping skills by specialists to deal with their condition as well as effective stress management strategies to help patients deal with other stressors in their lives.

\section{References}

[1] Abutiate, H. (2014, March 6th). Ghana tops glaucoma cases globally. Graphic Online.

[2] Beck, A.T., (1979).Cognitive therapy and the emotional disorders.New York: International University Press.

[3] Dawoda, O. A., Otakpor, A. N. \& Ukponmwan, C. U. (2004).Common psychiatric disorders in glaucomapatients as seen at the University of Benin Teaching Hospital, Benin City, Nigeria. A Journal of Biomedical Sciences, 3(1), 42-47.

[4] Debrah, O. (2014, October 18). Ghana A Leading Country with Glaucoma.Peacefmonline.

[5] DiMatteo, M. R., Lepper, H. S., \&Croghan, T. W. (2000). Depression is a risk factor for noncompliance with medical treatment: A meta-analysis of the effects of anxiety and depression on patient adherence. Archives of Internal Medicine, 160, 2101-2107.

[6] Eramudugolla, R., Wood, J., \& Anstey K. J. (2013). Co-morbidity of depression and anxiety in common age-related eye disease: a population-based study of 662 adults. Frontiers in Aging Neuroscience, 5, 56.10.3389/fnagi.2013.00056.

[7] Faal, H. (2012). Primary open-angle glaucoma: everyone's business. Community Eye Health, 25(79-80), 41-43. 
[8] Gostautas, A., Pranckeviciene, A., \&Matoniene, V. (2006).Changes in depression and quality of life during inpatient treatment of depression.Medicina (Kaunas), 42, 472-478.

[9] Kong, X. M., Zhu, W. Q., Hong, J. X., \&Sun, X. H. (2014). Is glaucoma comprehension associated with psychological disturbance and vision-related quality of life for patients with glaucoma? A cross-sectional study.BMJ Open, 4(5), e004632.

[10] Krishnadas, R., \&Puthuran, G.V. (2009).Prevalence of Glaucoma in India and the World.Available at: http://v2020eresource.org/sitenews/news072010/Prevelence.pdf [Accessed 18th June, 2015].

[11] Mabuchi, F., Yoshimura, K., Kashiwagi, K., et al. (2008).High prevalence of anxiety and depression in patients with primary open-angle glaucoma.Journal of Glaucoma, 17, 552- 557.

[12] Mabuchi, F., Yoshimura, K., Kashiwagi, K., et al. (2012).Risk factors for anxiety and depression in patients with glaucoma. British Journal of Ophthalmology, 96, 821-825.

[13] McKean, C. R, Wang, Y., Wu,J.,Azen, S. P., \&Varma, R. (2008). Impact of visual field loss on health-related quality of life in glaucoma: the Los Angeles Latino Eye Study. Ophthalmology, 115, 941-948.

[14] Nolen-Hoeksema, S. (2001).Gender Differences in Depression.Current directions in psychological science, 10(5), 173-176.

[15] Oles, M. \&Oles, P. (2014).Coping Style and Quality of Life in Elderly Patients with Vision Disturbances.Journal of Ophthalmology, 2014, 1-6.

[16] Pache, M.,\&Flammer, J. (2006).A sick eye in a sick body?Systemic findings in patients with primary open-angle glaucoma.Survey of Ophthalmology 51(3), 179-212.

[17] Pappa C., Hyphantis T., Pappa S., Aspiotis M., Stefaniotou M., Kitsos G., Psilas K. \&MavreasV. (2006). Psychiatric manifestations and personality traits associated with compliance with glaucoma treatment. Journal of Psychosomatic Research, 61(5), 609-617.

[18] Sandford-Smith J. (2004). Eye Diseases in Hot Climates (4th ed.) .Elsevier.pg 211.

[19] Segal, Z. V., Kennedy, S., Gemar, M., Hood, K., Pedersen, R., \&Buis, T. (2006). Cognitive reactivity to sad mood provocation and the prediction of depressive relapse.Archive of General Psychiatry, 63, 749-755.

[20] Selye, H. (1976). Stress in health and disease.Butterworth's, Inc. Boston, MA.

[21] Tastan, S., Iyigun, E., Bayer, A, et al. (2010).Anxiety, depression, and quality of life in Turkish patients with glaucoma.Psychological Report, 106, 343-357.

[22] Wang, S.Y., Singh, K., \& Lin, S. C. (2010). Prevalence and predictors of depression among participants with glaucoma in a nationally representative population sample. American Journal of Ophthalmology, 154, 436-444.

[23] Weiss, G.A.,Goldich, Y., Bartov, E., \&Burgansky-Eliash, Z. (2011).Compliance with eye care in glaucoma patients with comorbid depression.Israel Medical Association Journal, 13(12), 730 734.

[24] Wu, P.-X.,Guo, W.-Y., Xia, H.-O., Lu, H.-J.\& Xi, S.-X. (2011).Patients' experience of living with glaucoma: a phenomenological study.Journal of Advanced Nursing, 67(4), 800- 810.

[25] Zhou, C., Qian, S., Wu, P., \& Qui, C. (2013). Anxiety and depression in Chinese patients with glaucoma: socio-demographic, clinical, and self-reported correlates. Journal of Psychosomatic Research, 75, 75-82.

[26] Zhou, C., Qian, S., Wu, P. \&Qiu, C. (2014).Quality of life of glaucoma patients in China: sociodemographic, clinical, and psychological correlates - a cross-sectional study. Quality ofLife Research, 23, 999-1008.

*Corresponding author.

E-mail address: danielbruceyao@yahoo.co.uk 